\title{
Increased cytomegalovirus replication by 5-Azacytidine and viral-induced cytoplasmic expression of DNMT-1 in medulloblastoma and endothelial cells
}

\author{
ATOSA ESTEKIZADEH ${ }^{1,2}$, NATALIA LANDÁZUR ${ }^{1,2}$, JIRI BARTEK Jr ${ }^{2-4,6}$, \\ CHRISTIAN BELTOFT BRØCHNER ${ }^{4,5}$, BELGHIS DAVOUDI ${ }^{2}$, HELLE BROHOLM ${ }^{5}$, \\ MOHSEN KARIMI $^{2}$, TOMAS J.EKSTRÖM ${ }^{1}$ and AFSAR RAHBAR ${ }^{2}$ \\ ${ }^{1}$ Department of Clinical Neuroscience and Center for Molecular Medicine, Karolinska Institutet; \\ ${ }^{2}$ Department of Medicine, Solna and Center for Molecular Medicine, Karolinska Institutet; \\ ${ }^{3}$ Department of Neurosurgery, Karolinska University Hospital, SE_17176 Stockholm, Sweden; \\ Departments of ${ }^{4}$ Neurosurgery and ${ }^{5}$ Pathology, Copenhagen University Hospital Rigshospitalet; \\ ${ }^{6}$ Danish Cancer Society Research Centre, DK-2100 Copenhagen, Denmark
}

Received September 15, 2017; Accepted January 24, 2018

DOI: $10.3892 /$ ijo.2018.4286

\begin{abstract}
Among all brain tumors diagnosed in children, medulloblastomas (MBs) are associated with a poor prognosis. The etiology of MB is not fully understood, yet the impact of epigenetic alterations of oncogenes has previously been established. During the past decade, the human cytomegalovirus (HCMV) has been detected in several types of cancer, including MB. Since DNA methylation occurs in the cell nucleus and this is considered a host defence response, we studied the impact of HCMV infection on DNA methyltransferase (DNMT-1) in MB (D324) cells, human umbilical vein endothelial cells (HUVECs) as well as in MB tissue sections. We hypothesized that infection and DNMT-1 intracellular localization are linked. Uninfected and HCMV-infected D324 cells and HUVECs were analyzed for HCMV immediate early (HCMV-IE) protein, HCMV-glycoprotein B (HCMV-gB) and DNMT-1 using immunofluorescence staining and quantitative ELISA. DNMT-1 localized to the nucleus of uninfected and HCMV-IE- expressing D324 cells and HUVECs, but accumulated in the extra nuclear space in all HCMV-gB-positive cells. Inhibition of HCMV late protein expression by Cymevene ${ }^{\circledR}$ (ganciclovir) prevented the cytoplasmic localization of DNMT-1. Treatment of
\end{abstract}

Correspondence to: Dr Afsar Rahbar, Department of Medicine, Solna and Center for Molecular Medicine, CMM L8:03, 17176 Stockholm, Sweden

E-mail: afsar.rahbar@ki.se

Professor Tomas J. Ekström, Department of Clinical Neuroscience and Center for Molecular Medicine, Karolinska Institute, CMM L8:00, 17176 Stockholm, Sweden

E-mail: tomas.ekstrom@ki.se

Key words: human cytomegalovirus, medulloblastoma, DNMT-1, endothelial cells, 5-Azacytidine, ganciclovir
HCMV- infected D324 cells and HUVECs with the methylation inhibitor 5-Azacytidine (5AZA), significantly increased HCMV-IE and HCMV-gB gene transcription and protein expression. Immunohistochemical staining of DNMT-1 and HCMV proteins in MB cancer tissue sections revealed both nuclear and cytoplasmic DNMT-1 localization. In conclusion, DNMT-1 resides in the cytoplasm of HCMV-gB-expressing HUVECs and D324 cells. Increased viral protein synthesis in 5AZA-treated cells suggests that HCMV replication may benefit from a DNA methyltransferase-free cellular environment. Our findings emphasize the importance of assessing potential viral activation in the treatment of MB patients with epigenetic drugs.

\section{Introduction}

Among childhood cancers, brain tumors account for almost one-third of all cancer-related deaths. Medulloblastomas (MBs) demonstrate a poor prognosis despite advanced therapies consisting of surgery, radiotherapy and chemotherapy, sometimes followed by stem cell transplantation $(1,2)$. The long-term survival ( $>5$ years) rate of MB patients with high-risk disease is $60-65 \%$ (3). MB patients often experience complications related to aggressive treatment regimens, including developmental, neurological and psychosocial deficits. There is thus an unmet medical need for the development of new and effective treatments with minimal damage to the developing brain in these children (4). MBs develop in the cerebellum or brainstem and spread through the cerebrospinal fluid along the neuroaxis, but rarely to organs outside the central nervous system (CNS). The etiology of MB is not fully understood but the impact of environmental factors such as diet, pathogens, exposure to radiation and hereditary genetic defects have previously been reported (5). Together with clinical factors (e.g. subtotal tumor resection), receptor tyrosine kinase (RTK) expression and loss of genetic material at chromosome $17 \mathrm{p}$ have been associated with a poor prognosis. 
Two of the four currently recognized clinical variants of MB involve the WNT/ $\beta$-catenin and the Sonic hedgehog $(\mathrm{SHH})$ pathways (6). SHH signaling synergizes with the insulin-like growth factor 2 (IGF-II) to promote MB as well as cerebellar neural precursor cell proliferation (7). The two non-WNT/ SHH MB variants, with particularly unfavorable prognosis, are designated as group 3 and 4 tumors, respectively, and exhibit frequent expression of follistatin (FSTL5) (8), elevated Myc (9) and GFI1 (10) expression. Although a rare finding, recent data have demonstrated that MB presents with subgroup-related mutations, some of which have direct epigenetic effects such as regulation of histone $\mathrm{H} 3 \mathrm{~K} 27$ and $\mathrm{H} 3 \mathrm{~K} 4$ methylation as evident for group 3 and 4 MBs (11). These data underscore the importance of epigenetic mechanisms and the notion that environmental factors (also during fetal life) working through epigenetic mechanisms may be the underlying factors for the disease etiology. Indeed, recent comprehensive epigenetic analyses of MBs emphasize the importance of epigenetic alterations in the pathogenesis of the various MB subtypes $(12,13)$.

Specific changes in DNA methylation is a hallmark of many cancers and can cause genomic instability and/or changes in gene expression $(14,15)$. In vertebrates, DNA methylation is mediated by DNA methyltransferase enzymes (DNMTs), through transfer of a methyl group from S-adenosylmethionine (SAM) to the C-5 position of cytosine residues in $\mathrm{CpG}$ dinucleotide sequences $(16,17)$. In mammals, the DNMT family has three active members: DNMT-1, which is required for the maintenance of methylation in the genome through the replication process, and DNMT3A and DNMT3B, which are regarded as de novo methyltransferases (18).

During recent years HCMV protein and nucleic acid have been detected in several types of tumor tissues, including glioblastoma, neuroblastoma and medulloblastoma (19-22). HCMV is a widespread $\beta$-herpesvirus carried by $60-95 \%$ of adults worldwide in both developing and developed countries and establishes a lifelong latency and persistence in myeloid lineage cells with periodic reactivation (23). HCMV infection is generally asymptomatic in immunocompetent hosts, but active viral infection is of considerable clinical importance in immunocompromised individuals such as organ transplant recipients, AIDS patients, and in congenitally infected newborns $(24,25)$. There is currently a poor understanding of the epigenetic mechanisms of host cells involved in HCMV infection. It has been reported that herpesvirus chromatin undergoes dynamic changes in structure and histone modifications during different stages of viral replication, latent infection and reactivation. Epigenetic events and states may hence dictate the outcome of infection in permissive cells $(26,27)$. Furthermore, previous studies have suggested a role for epigenetic alterations in HCMV latency by histone deacetylation and chromatin condensation (26). We previously reported that HCMV infection alters the DNA methylation machinery in susceptible non-tumor cells and changes the intracellular localization of DNMTs in vitro, resulting in a profound reduction in DNA methylation capacity (27).

In the present study, we sought to explore the effect of HCMV infection on DNMT-1 in MB cells and tumor biopsies as well as in human endothelial cells since vessels within the MB tumors most often express HCMV proteins and are important for tumorigenesis. Our data demonstrated that cytoplasmic localization of DNMT-1 in HCMV-infected MB and endothelial cells was associated with expression of HCMV late gene UL-55 (glycoprotein B, gB). An increased number of cells expressing viral proteins in 5-Azacytidine (5AZA)treated infected cells suggest that HCMV replication may benefit from inhibition of the host cell nuclear methylation machinery.

\section{Materials and methods}

Cell culture and HCMV infection. The human medulloblastoma cell line D324 (American Type Culture Collection (ATCC); LGC Standards, Teddington, UK) was cultured in Dulbecco's modified Eagle's medium (DMEM) supplemented with $10 \%$ heat-inactivated fetal bovine serum (FBS), 100 units penicillin and $100 \mu \mathrm{g}$ streptomycin (all from Gibco BRL; Thermo Fisher Scientific, Inc., Waltham, MA, USA) at $37^{\circ} \mathrm{C}$ in a humidified $5 \% \mathrm{CO}_{2}$ atmosphere. Human umbilical vein endothelial cells (HUVECs, ATCC) were grown in EBM2 endothelial basal medium supplemented with EGM-2 SingleQuots ${ }^{\circledR}$ (Clonetics $^{\mathrm{TM}}$; Lonza, Walkersville, MD, USA). Both D324 cells and HUVECs were infected at $80 \%$ confluency with the HCMV clinical strain VR1814 (a kind gift from Dr Giuseppe Gerna, University of Pavia, Pavia, Italy) at a multiplicity of infection (MOI) of 5 , for $72 \mathrm{~h}$. All experiments in this study were performed as three independent experiments.

5-Azacytidine treatment (5AZA). D324 cells and HUVECs were seeded in 8-well chamber slides (VWR, Radnor, PA, USA), and at $\sim 80 \%$ confluency, the cells were left untreated or treated with 5AZA (10 $\mu \mathrm{M}$ for D324 cells and $2 \mu \mathrm{M}$ for HUVECs) (Sigma, Stockholm, Sweden) for 3 days. Untreated and 5AZA-treated cells were left uninfected or infected with HCMV-VR1814 at MOI 5, for $72 \mathrm{~h}$. At 3 days post-infection ( $3 \mathrm{dpi})$, the cells were fixed in ice-cold acetone:methanol (1:1) for $10 \mathrm{~min}$ and kept at $-20^{\circ} \mathrm{C}$.

Ganciclovir treatment. Uninfected and HCMV-infected D324 cells and HUVECs were left untreated or treated with $2 \mathrm{mM}$ ganciclovir (Cymevene ${ }^{\circledR}$, Roche, Basel, Switzerland) starting at the time of infection of the cells. Cells were fixed as described above.

Immunofluorescence staining. Immunofluorescence staining of the cells was performed as previously described, with minor modifications (27). After blocking of non-specific binding with protein blocker (Dako, Glostrup, Denmark), the cells were incubated with primary antibodies for $1 \mathrm{~h}$ at $4^{\circ} \mathrm{C}$. Binding of the primary antibodies was detected using fluorochrome-conjugated secondary antibodies incubated for $45 \mathrm{~min}$ at room temperature (RT). The nuclei of the cells were visualized using 4',6-diamidino-2-phenylindole (DAPI, Vectashield, Vector Laboratories, Burlingame, CA, USA), and coverslips were mounted using Dako Fluorescence Mounting Medium (Agilent Technologies, Inc., Santa Clara, CA, USA). The following primary and secondary antibodies were used for detection of specific target proteins: mouse anti-immediate early monoclonal antibody (at dilution 1:100, 11-003, Argene, 
Table I. Characteristics of the medulloblastoma tumors.

\begin{tabular}{|c|c|c|c|}
\hline Patients & Initial diagnosis & $\begin{array}{l}\text { New classification - } \\
\text { immunoreactivity }\end{array}$ & $\begin{array}{c}\text { New classification - } \\
\text { subgroup type }\end{array}$ \\
\hline
\end{tabular}

Patient 1 Classical MB, that recurred in a supratentorial supratentorial location the year after. A primitive neuroectodermal tumor is considered

Patient 2 Recurring classical MB. No information about location

Patient 3 Autopsy: Metastasizing classical MB which had spread to the cerebrum, in the areas around the lateral ventricles and in the pons and cerebellum

Patient 4 Classical MB

Patient 5 Classical MB. No loss of chromosome 1p/19q
Membranous $\beta$-catenin reactivity. Non-WNT/non-SHH (group 3/4) YAP-1 negative. P53 wild-type

Membranous and nuclear

WNT-activated

$\beta$-catenin reactivity. YAP-1

positivity in areas. P53 wild-type

Membranous $\beta$-catenin reactivity. Non-WNT/non-SHH (group 3/4) YAP-1 negative. P53 wild-type

Membranous and nuclear $\beta$-catenin WNT-activated reactivity. YAP-1 positivity in areas. P53 wild-type

Membranous $\beta$-catenin reactivity. SHH-activated, p53 wild-type YAP-1 positivity. P53 wild-type

MB, medulloblastoma; SHH, sonic hedgehog; YAP-1, yes-associated protein 1.

Verniolle, France); mouse monoclonal antibody to gB (dilution 1:50, P1216, Virusys Corporation, Taneytown, MD, USA); rabbit antibody to DNMT-1 (dilution 1:500, 19905, Abcam, Cambridge, UK); Alexa Fluor-488-conjugated goat anti-mouse (dilution 1:500, A11001, Life Technologies, Eugene, OR, USA); and Texas red conjugated goat anti-rabbit (dilution 1:500; Life Technologies, T2767). Omitting primary antibodies was used as the negative control.

Evaluation of the staining was performed with confocal microscope (Leica TCS SP5) equipped with Leica Application Suite Advanced Fluorescence software (Leica Microsystems, Wetzlar, Germany).

RNA extraction and quantitative TaqMan PCR ( $q P C R)$. RNA was isolated from the cultured cells using Allprep DNA/RNA/ protein mini kit and/or RNeasy kit (Qiagen, Stockholm, Sweden) according to the manufacturer's instructions. The concentrations of RNA were measured using NanoDrop ND-1000 spectrophotometer (Thermo Scientific). Isolated RNA (500 ng) was converted to cDNA using Superscripts III First-Strand Synthesis System (Invitrogen, Stockholm, Sweden) using random hexamers according to the manufacturer's application manual.

TaqManFast UniversalPCR MasterMix(Life Technologies; Thermo Fisher Scientific) was used with the following primers/probes: HCMV-IE (forward primer, TGACGAGGGC CCTTCCT; reverse primer, CCTTGGTCACGGGTGTCT and probes, FAM-AAGGTGCCACGGCCCG-NFQ) and HCMV-gB (forward primer, GCTACCGCCCTACCTCAAG; reverse primer, CGCCAACGGCCTTTCC and probes, FAM-CCCAGGCCGCTCATG-NFQ) and DNMT-1 (assay ID,Hs00945875_m1, Life Technologies; Thermo Fisher Scientific). RNase P (assay ID, 4316844, Life Technologies,
Thermo Fisher Scientific) and $\beta_{2}$-microglobulin (B2M, assay ID, Hs00984230_m1, Thermo Fisher Scientific) were used for normalization. The qRT-PCR was performed using an Applied Biosystems 7900HT fast real-time PCR system (Thermo Fisher Scientific) and the results were analyzed with SDS 2.4 software (Applied Biosystems; Thermo Fisher Scientific). The $\Delta \mathrm{CT}$ method was used for calculation of CT values for different transcripts. The $2^{-\Delta \Delta C T}$ method was used to quantify relative fold changes.

Quantification of DNMT-1. The concentration of DNMT-1 in cell lysates was measured using the DNMT-1 human ELISA kit (SKU: K4195, BioVision Incorporated, Milpitas, CA, USA) in accordance with the manufacturer's instructions.

Immunohistochemical staining (IHC). Paraffin-embedded human MB tumor tissue sections from 5 patients were obtained from the Department of Pathology at Rigshospitalet, Copenhagen, Denmark. Information regarding the tumor characteristics is documented in Table I.

Ethical permission for the present study protocol was granted by the Local Ethics Committee at Region Hovedstaden, Denmark (H-6-2014-010) and the Local Ethics Committee at Karolinska Institutet, Sweden (Dnr. 2008/628-31).

Immunohistochemical staining of the tissues was performed as previously described $(19,20)$. Briefly, all sections were first deparaffinized in xylene and rehydrated in a series of decreasing concentrations of ethanol and were then treated with pepsin (BioSite, Täby, Sweden) and citrate buffer (Biogenex, CA, USA) to retrieve the epitopes. Endogenous peroxidase activity was blocked with $3 \% \mathrm{H}_{2} \mathrm{O}_{2}$ (Sigma-Aldrich; Merck KGaA, Darmstadt, Germany). In addition, the sections were treated with Avidin/Biotin blocker 
A
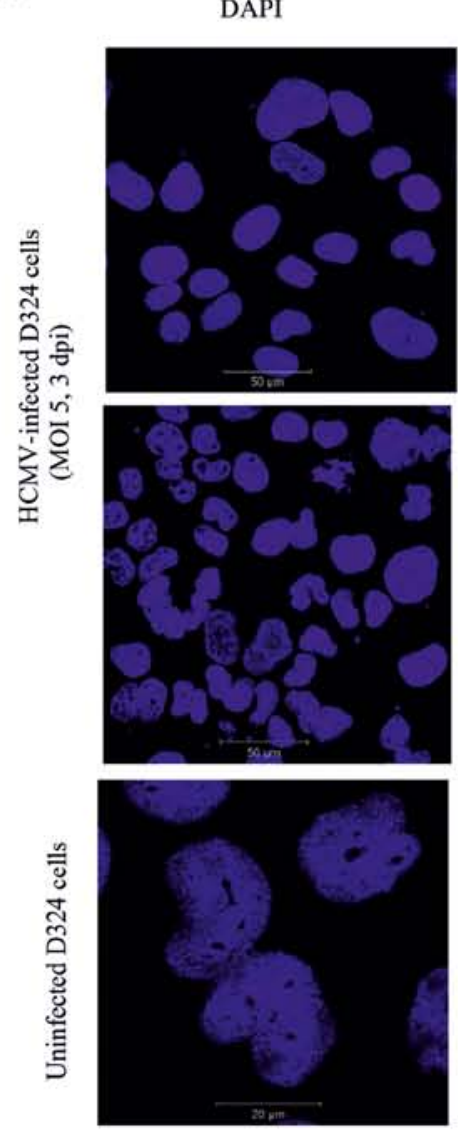

B
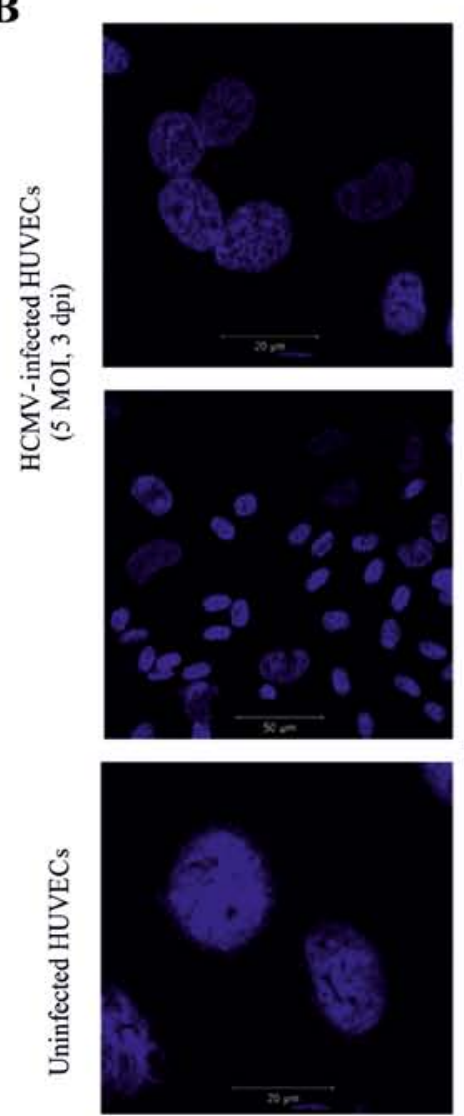

HCMV

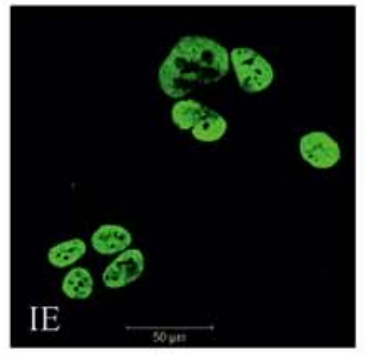

gB
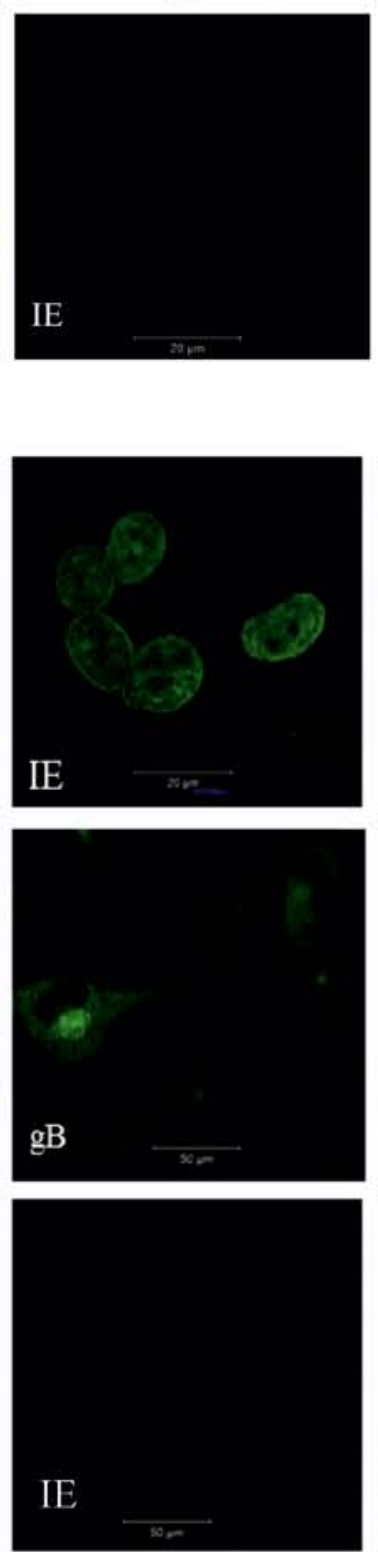

DNMT-1
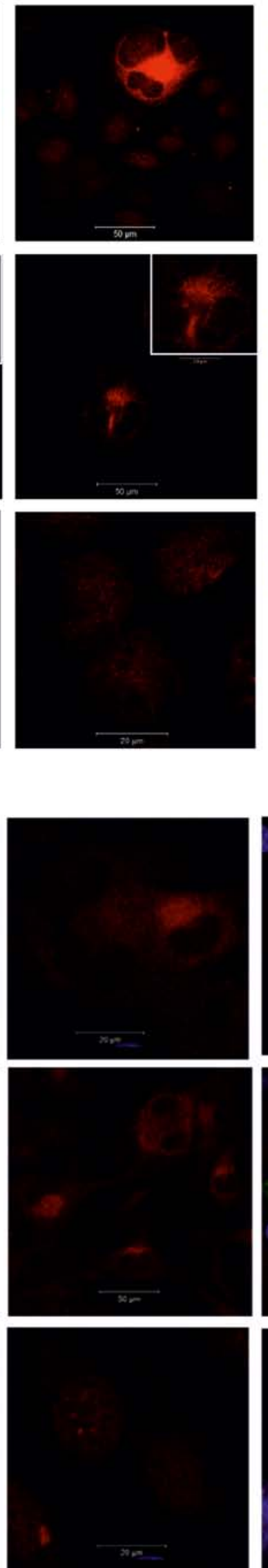
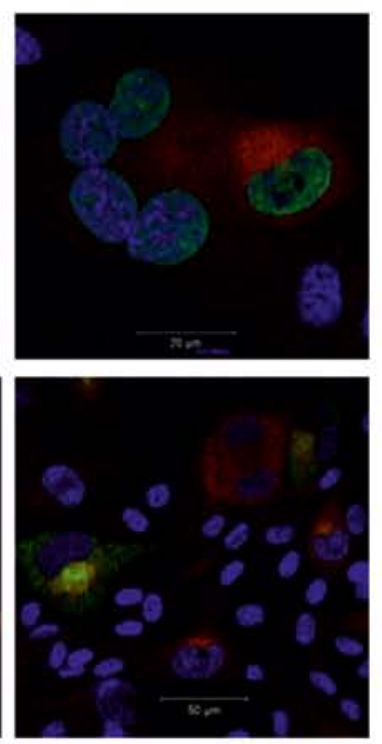

Merged
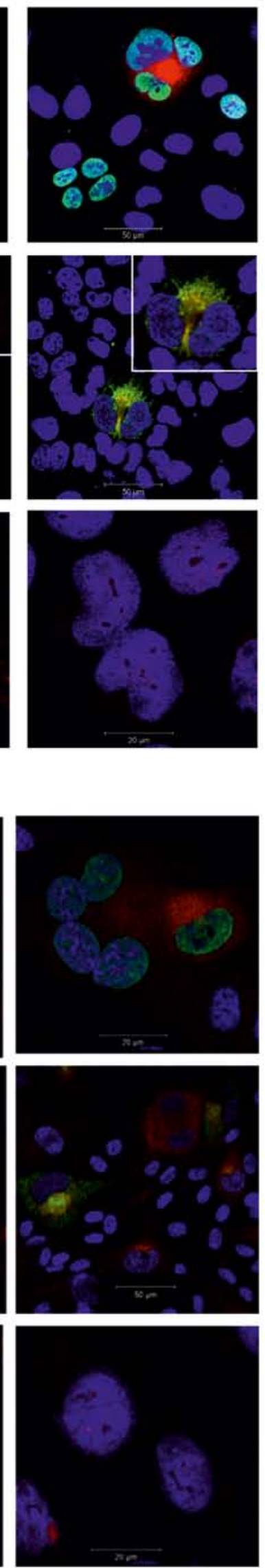

Figure 1. Nuclear and cytoplasmic localization of DNMT-1 in HCMV-infected D324 cells and HUVECs. Immunostaining demonstrating DNMT-1 in cells expressing HCMV-IE and HCMV-gB. DNMT-1, DNA methyltransferase 1; HCMV, human cytomegalovirus; HCMV-IE, HCMV immediate early; HCMV-gB, HCMV-glycoprotein B; HUVECs, human umbilical vein endothelial cells. 
A

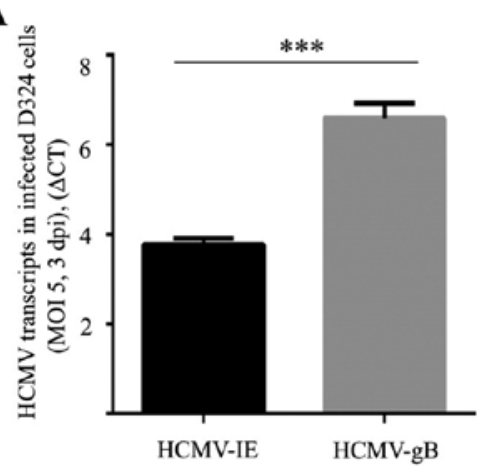

$\mathbf{D}^{\frac{5}{2}}$

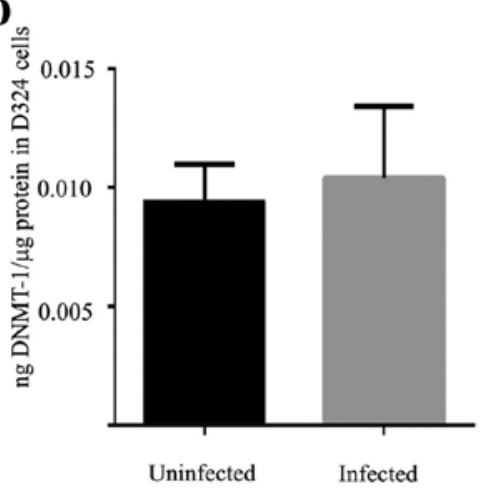

B

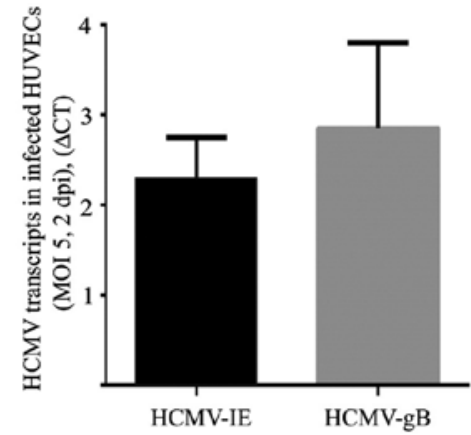

$\mathbf{E}$

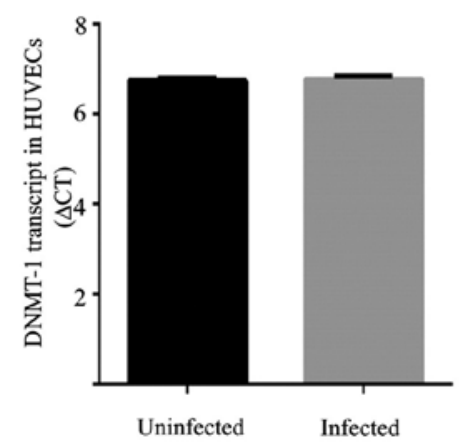

C

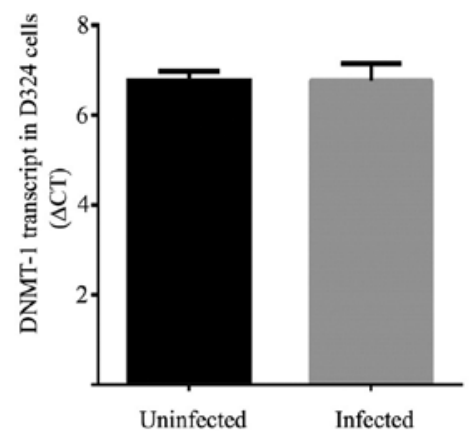

$\mathbf{F}$

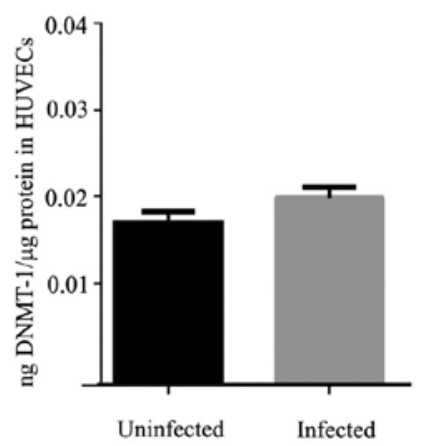

Figure 2. Evaluation of HCMV infection in D324 cells and HUVECs. (A, C and D) DNMT-1, HCMV-IE and HCMV-gB mRNA and protein expression in infected D324 cells and (B, E and F) HUVECs. DNMT-1, DNA methyltransferase 1; HCMV, human cytomegalovirus; HCMV-IE, HCMV immediate early; HCMV-gB, HCMV-glycoprotein B; HUVECs, human umbilical vein endothelial cells.

(Dako Avidin/Biotin Blocking kit; Agilent Technologies), Fc receptor blocker and Background Buster (Innovex Biosciences, Richmond, CA, USA) to eliminate non-specific binding. The slides were incubated with the primary antibodies: HCMV, IE (MAB810R, Merck, Stockholm, Sweden), gB (a kind gift from Dr William Britt, University of Alabama, AL, USA) or DNMT-1 (19905, Abcam), at $4^{\circ} \mathrm{C}$ overnight and after washing the specific epitopes were detected with ImmPRESS reagent kits (MP-7401 and MP-7402, Vector Laboratories) and diaminobenzidine (DAB, NB314D, Innovex Biosciences). Omitting the primary antibodies was used as the negative control. Hamamatsu Nano Zoomer-XR Digital slide scanner C12000 with visualization using Nano Zoomer Digital Pathology (NDP) viewer software (U12388-01; NDP.view2 Viewing) was used for scanning of the sections.

Statistical analysis. All analyses were performed using GraphPad Prism (GraphPad Software, San Diego, CA, USA). $\mathrm{P}<0.05$ was considered to indicate a statistically significant difference. Unpaired t-test and Mann-Whitney U test were used to assess the statistical significance between different variables.

\section{Results}

Cytoplasmic location of DNMT-1 in the HCMV-gB-expressing cells. We examined DNMT-1 protein expression and localization in the uninfected and HCMV-infected MB D324 cells and HUVECs. HUVECs were included in this study since endothe- lial cells of blood vessels are a major reservoir of HCMV with the capacity to influence hemostasis and co-infection of other cells through cell-cell contact. DNMT-1 was weakly visible in the nucleus of all uninfected cells and in infected cells that expressed only HCMV-IE, but was almost exclusively localized in the cytoplasm of HCMV-gB-positive cells (Fig. 1A and $\mathrm{B}$ ). qPCR analysis revealed a significantly higher number of HCMV-gB transcripts compared to HCMV-IE transcripts in infected D324 cells ( $\mathrm{P}=0.0002$, Fig. 2A). Equal numbers of transcripts of HCMV-IE and HCMV-gB were detected in HUVECs (Fig. 2B). For DNMT-1, neither the transcripts nor the protein levels of DNMT-1 differed between uninfected and HCMV-infected cells (Fig. 2C-F).

Maintenance of DNMT-1 nuclear localization in ganciclovirtreated HCMV-infected D324 cells but not in HUVECs. HCMV-infected D324 cells and HUVECs were treated with ganciclovir. As expected, HCMV-IE protein was expressed while HCMV late gene expression (represented by HCMV-gB) was inhibited in the treated cells (Fig. 3A and B). In HCMV-infected and ganciclovir-treated D324 cells, DNMT-1 was only expressed in the nucleus of the cells (Fig. 3A). In contrast, the HCMV-infected HUVECs did not respond to ganciclovir in the same way, but displayed a cytoplasmic DNMT-1 localization similar to the untreated cells (Fig. 3B).

HCMV and DNMT-1 gene and protein expression in the 5AZA-treated D324 cells and HUVECs. Uninfected and 
A
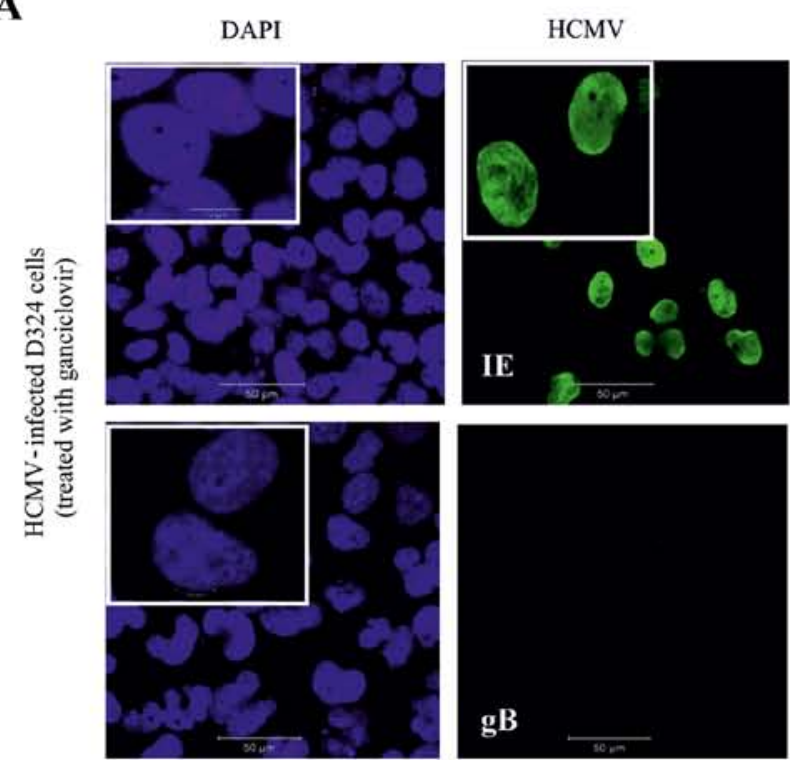

DNMT-1
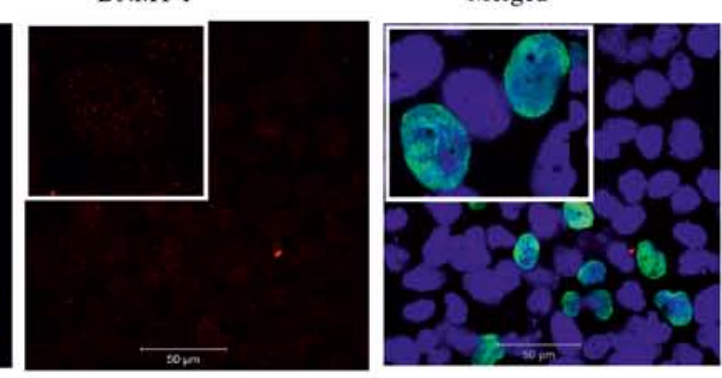

gB
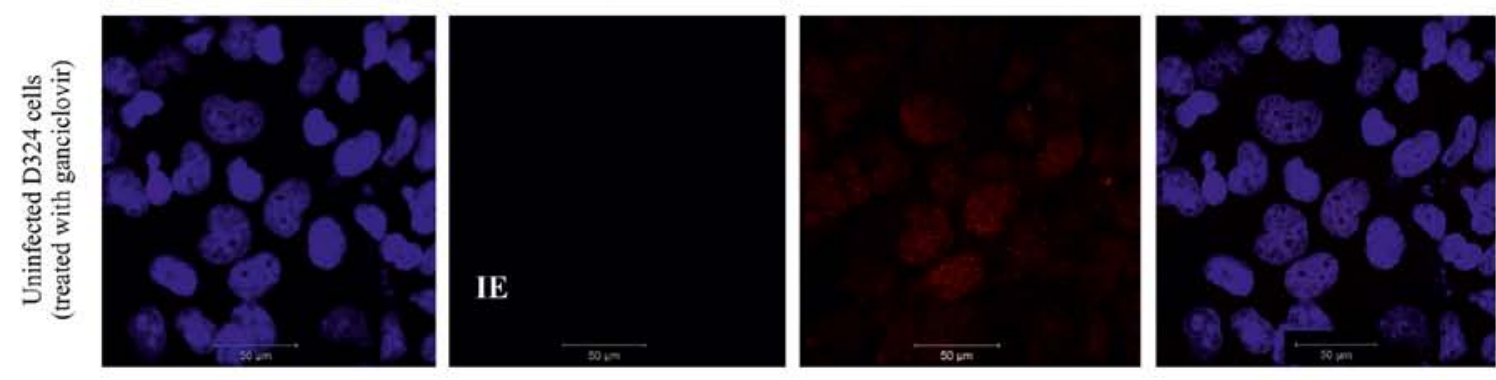

\section{B}
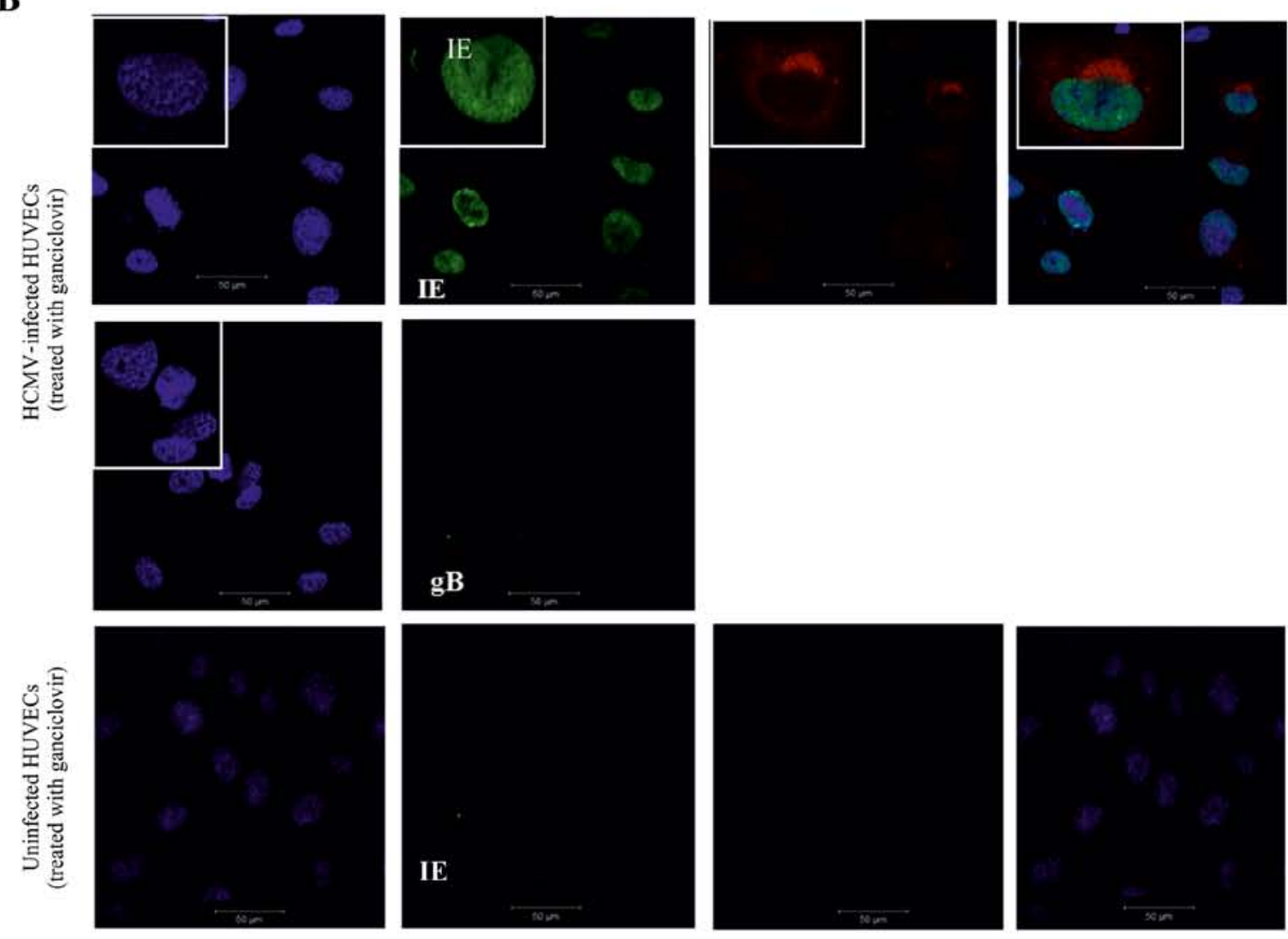

Figure 3. Maintenance of DNMT-1 nuclear localization in ganciclovir-treated HCMV-infected D324 cells but not in HUVECs. HCMV-infected (A) D324 cells and (B) HUVECs were treated with ganciclovir, followed by immunostaining to assess cellular distribution of DNMT-1, HCMV-IE and HCMV-gB. DNMT-1, DNA methyltransferase 1; HCMV, human cytomegalovirus; HCMV-IE, HCMV immediate early; HCMV-gB, HCMV-glycoprotein B; HUVECs, human umbilical vein endothelial cells. 
A
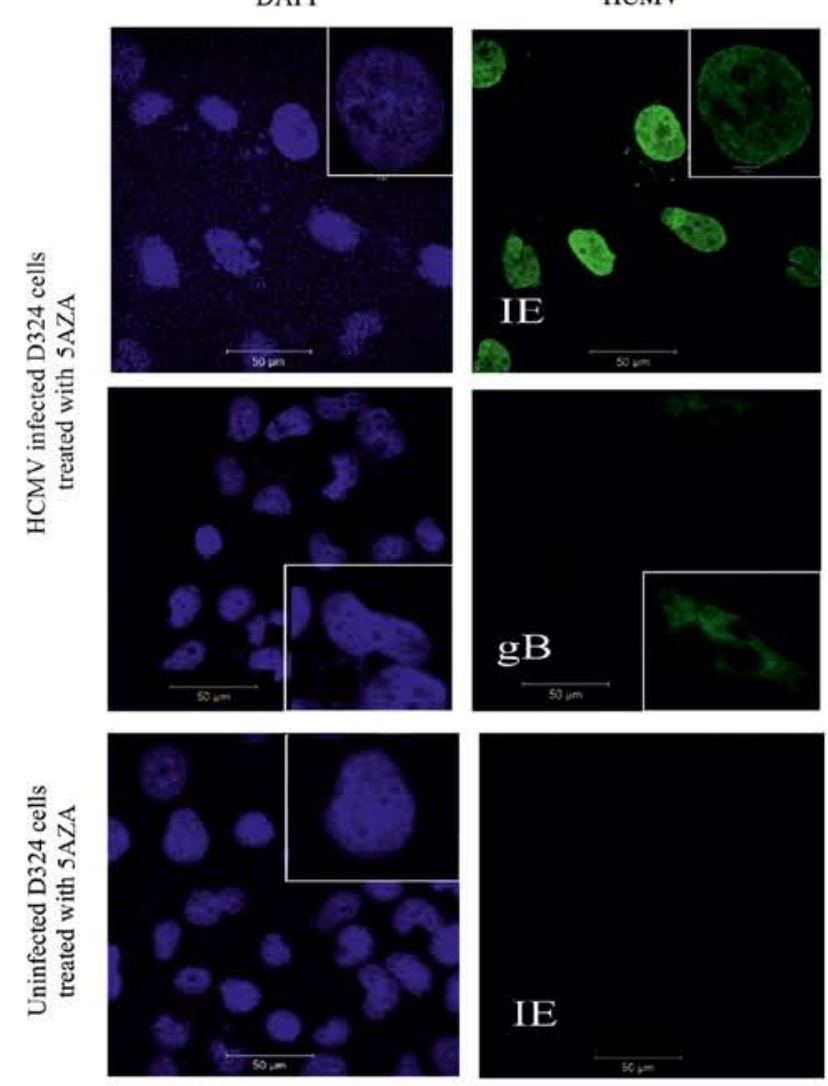

DNMT-1
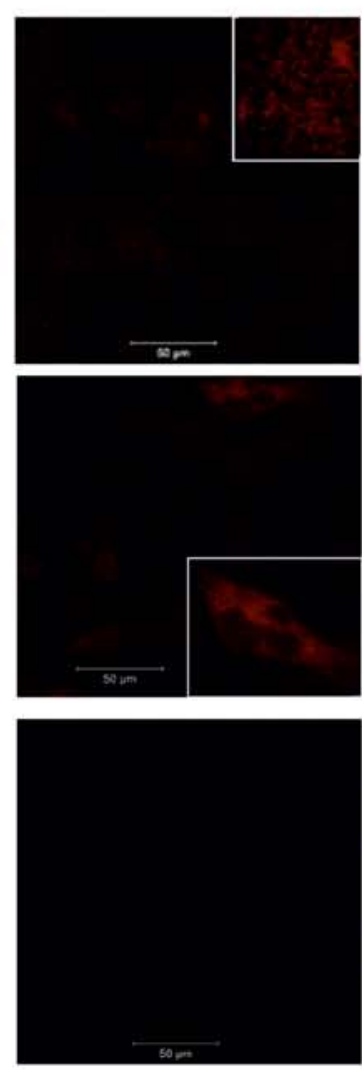

Merged
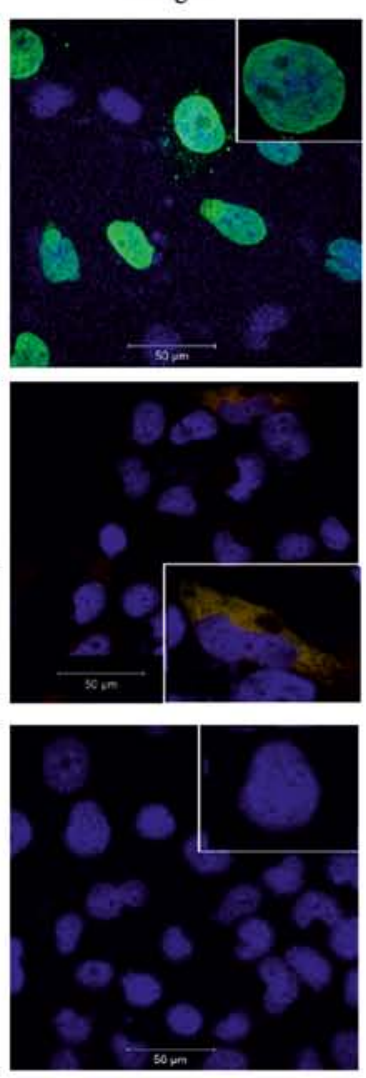

B

HCMV
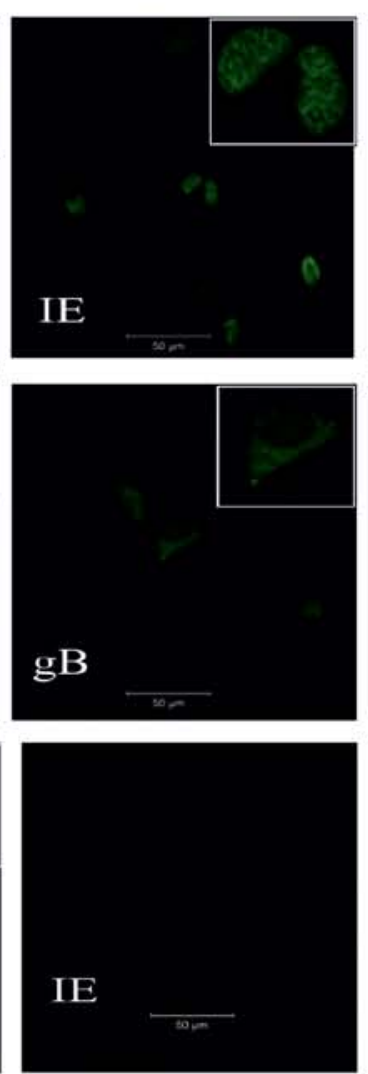

DNMT-1
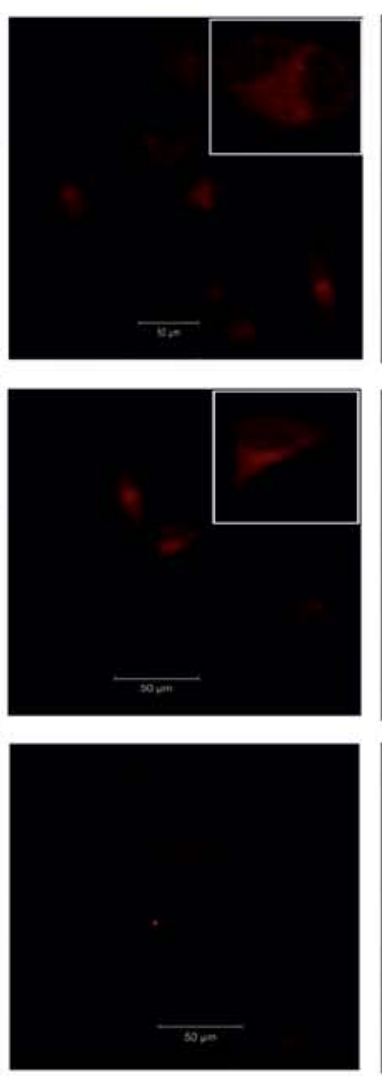

Merged
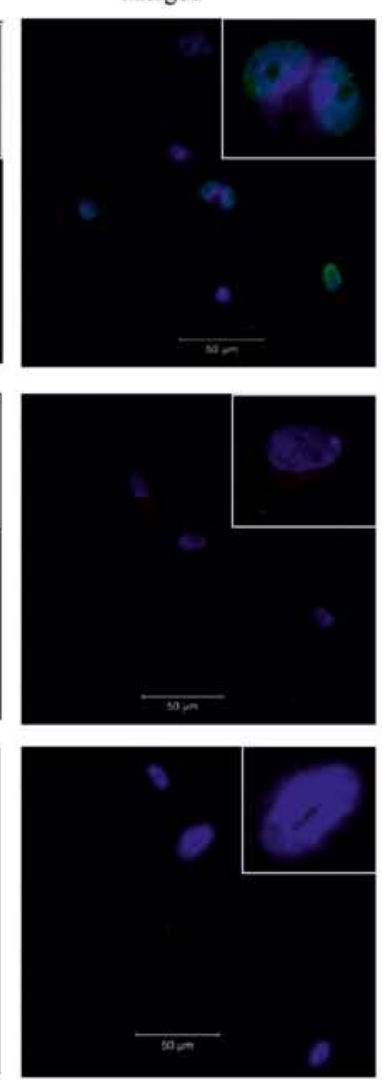

Figure 4. Immunostaining of HCMV proteins and assessment of mRNA levels of HCMV-IE, HCMV-gB, and DNMT-1 in 5AZA -treated D324 cells and HUVECs. (A) D324 cells and (B) HUVECs were treated with 5AZA followed by HCMV infection. 
C

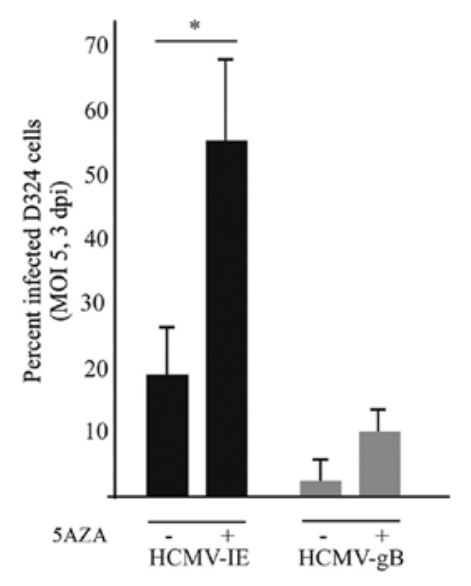

$\mathbf{E}$

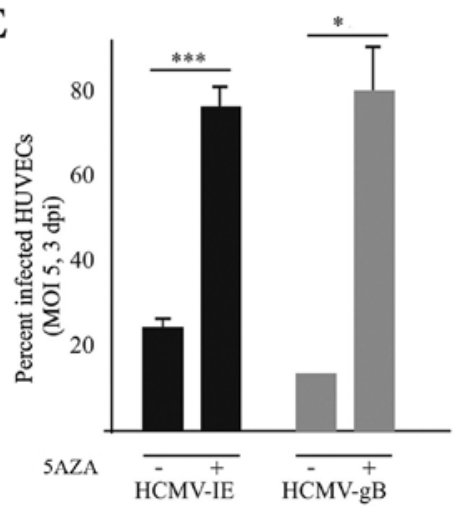

D

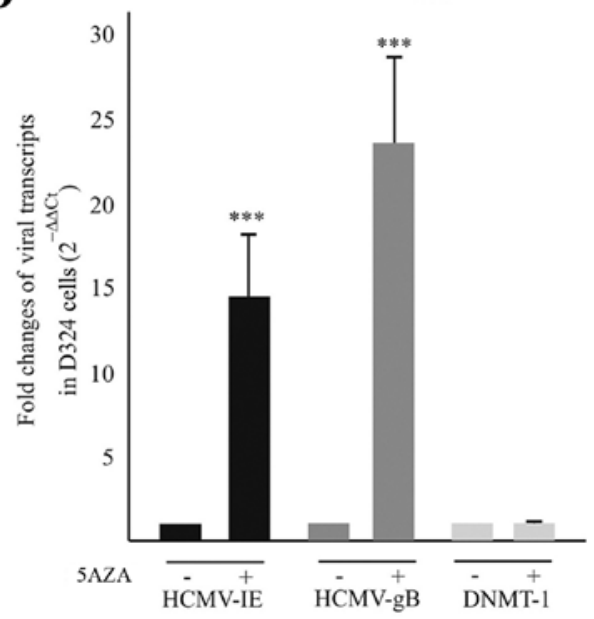

F

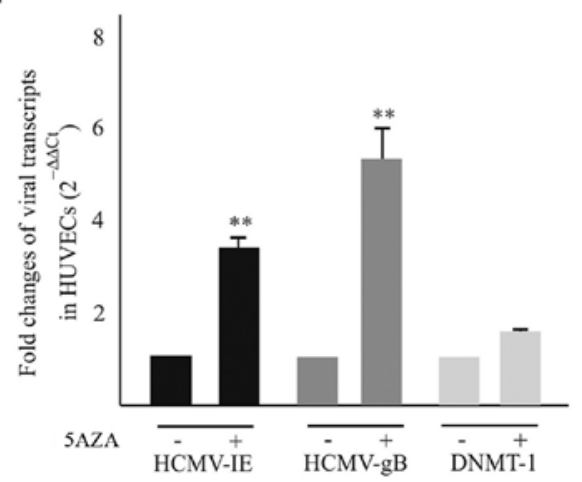

Figure 4. Continued. Immunostaining was followed (A and B) and assessment of the number of infected (IE or $\mathrm{gB}$ ) cells relative to DAPI stained cells was performed for D324 cells (C) and HUVECs (E). Quantitative PCR for IE, gB and DNMT-1 in D324 cells and HUVECs is depicted as fold-change compared to the untreated cells (D and F). DNMT-1, DNA methyltransferase 1; HCMV, human cytomegalovirus; HCMV-IE, HCMV immediate early; HCMV-gB, HCMV-glycoprotein B; HUVECs, human umbilical vein endothelial cells; 5AZA, 5-Azacytidine.

HCMV-infected D324 cells and HUVECs were treated with 5AZA and analyzed for the expression of HCMV and DNMT-1 proteins and transcripts (Fig. 4). In HCMV-infected and 5AZA -treated D324 cells the proportion of HCMV-IE-positive cells was significantly increased compared to the untreated cells $(\mathrm{P}=0.01)$ (Fig. 4C) while the proportion of HCMV-gB-positive cells was not significantly increased $(\mathrm{P}=0.09)$ (Fig. 4C). Based on qPCR analysis, the expression of HCMV-IE and HCMV-gB transcripts was significantly increased by $5 \mathrm{AZA}$ treatment in the D324 cells compared to those in the untreated cells ( $\mathrm{P}=0.0002, \mathrm{P}=0.0003$, respectively) (Fig. 4D). The number of HCMV-IE and HCMV-gB protein-positive HUVECs were significantly increased following 5AZA treatment, indicating enhanced infection efficiency $(\mathrm{P}=0.0005$ and $\mathrm{P}=0.04$, respectively) (Fig. 4E). HCMV-IE and HCMV-gB transcripts were significantly increased in the 5AZA-treated HCMV-infected HUVECs compared to those in the untreated cells $(\mathrm{P}=0.004$, $\mathrm{P}=0.008$, respectively) (Fig. 4F).

Frequent detection of HCMV-IE, HCMV-gB and DNMT-1 in medulloblastoma tissue specimens. MB tissue sections were immunohistochemically analyzed for HCMV-IE, HCMV-gB and DNMT-1. HCMV-IE and HCMV-gB proteins were frequently detected at different levels in all the examined $\mathrm{MB}$ tissues. Fig. 5 depicts one of the cases (patient no. 5, Table I). While DNMT-1 was detected in the nucleus of the majority of the tumor cells, cytoplasmic expression of DNMT-1 was detected in vessel walls within the tumors and in a few tumor cells within the tissues (Fig. 5).

\section{Discussion}

In the present study, we examined the interdependence of HCMV-IE, HCMV-gB proteins and DNMT-1 in MB cells. In concordance with our previous report of human fibroblasts (27), HCMV-infected D324 cells and HUVECs exhibited cytoplasmic localization of DNA methyltransferase DNMT-1, which correlated with the expression of HCMV late protein $\mathrm{gB}$ (UL55). Interestingly, while not all cells expressing IE genes had DNMT-1 located in the cytoplasm, all cells expressing the late gene product $\mathrm{gB}$ displayed cytoplasmic DNMT-1. Furthermore, ganciclovir treatment (which inhibits expression of late viral proteins) attenuated the cytoplasmic localization of DNMT-1 in HCMV-infected D324 cells, indicating an involvement of HCMV late genes/products in the extranuclear accumulation. Conversely, HCMV-infected HUVECs treated with ganciclovir still maintained a cytoplasmic distribution of DNMT-1, implying the involvement of different mechanisms 
DNMT-1
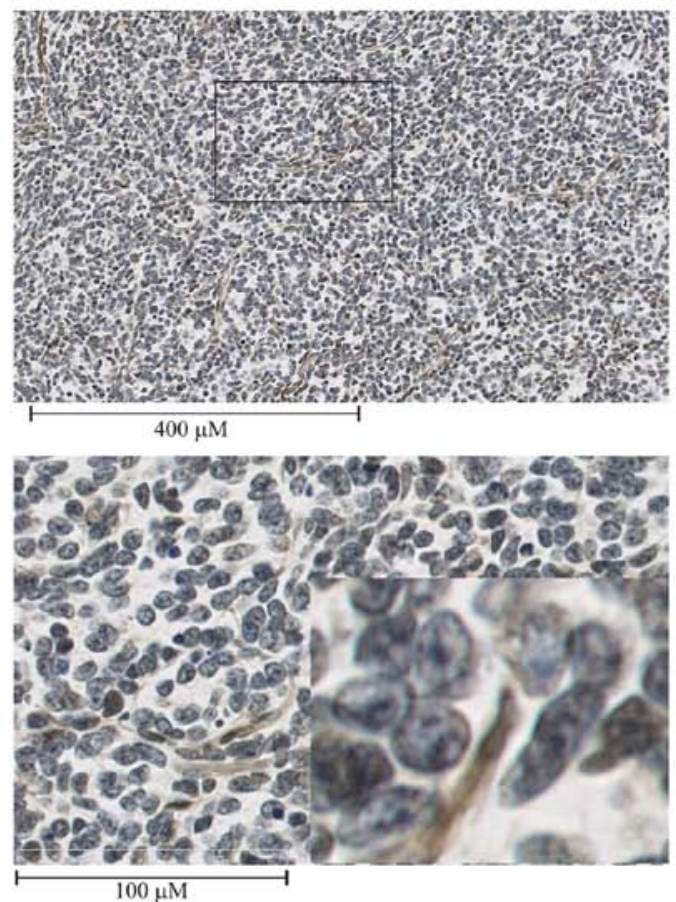

HCMV-gB
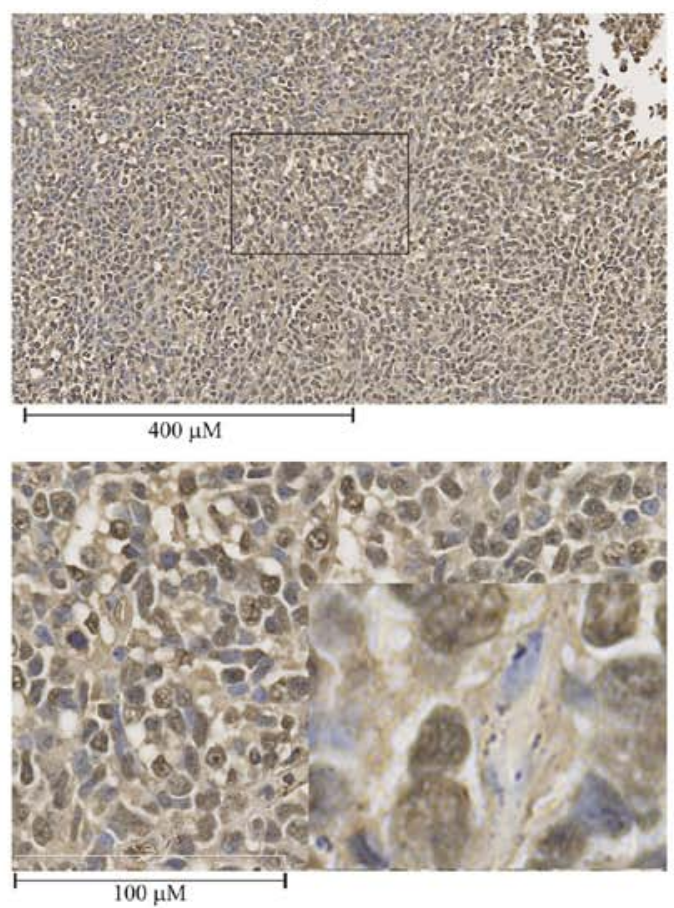

HCMV-IE
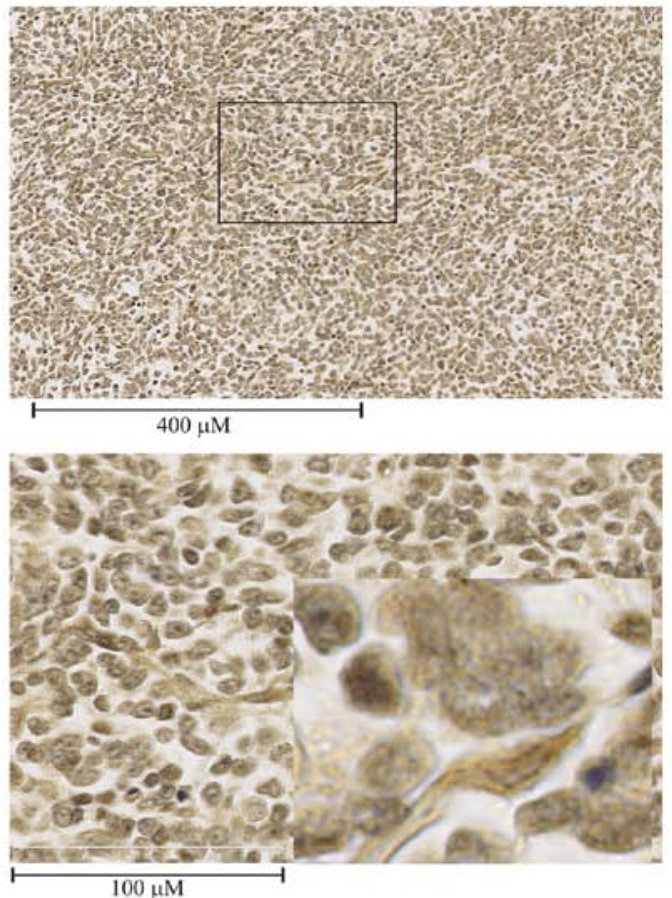

Neg. control
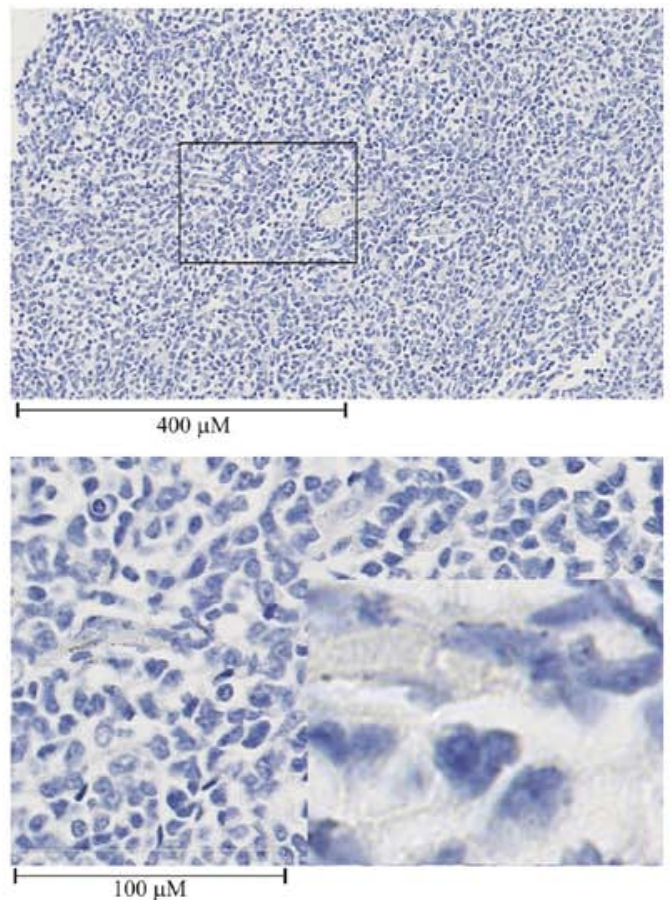

Figure 5. Detection of HCMV-IE, HCMV-gB and DNMT-1 in a medulloblastoma tissue specimen. MB tissue sections were analyzed for HCMV-IE, HCMV-gB and DNMT-1 by immunohistochemistry. The figure depicting tissue from patient no. 5 (Table I) demonstrates an example of DNMT-1 detection in the nucleus of the majority of tumor cells and cytoplasmic expression of DNMT-1 in vessel walls within the tumors and in a few tumor cells within the tissues. MB, medulloblastoma; DNMT-1, DNA methyltransferase 1; HCMV, human cytomegalovirus; HCMV-IE, HCMV immediate early; HCMV-gB, HCMV-glycoprotein B.

in this process. We hence suggest an association between HCMV infection in medulloblastoma (MB) and endothelial cells and the epigenetic modifier enzyme DNMT-1.

Tumor cells are generally characterized by global hypomethylation, and local hypermethylation of certain gene promoters such as tumor-suppressor genes (28). The relationship between DNA methylation alteration and human diseases, and its role in carcinogenesis has been established (15). DNMT-1 is required for the maintenance of DNA methylation in the genome (29). Its cytoplasmic localization in HCMV-infected cells might thus prevent normal gene methylation maintenance, which may influence the cellular behavior important for tumorigenesis and tumor development. During the past decade the impact of epigenetic modification in MB has been intensively discussed and investigators have reported epigenetic alterations in candidate tumor-suppressor genes including RASSF1A, 
CASP8, and $\mathrm{HIC} 1$ in $>30 \%$ of MB (30). Epigenetic silencing of tumor-suppressor genes as a contributor to tumorigenesis and development of MB thus emphasizes the importance of epigenetic mechanisms for novel diagnostic and therapeutic approaches (12).

Epigenetic mechanisms, such as methylation of DNA cytosine residues and post-translational modifications of histone proteins associated with DNA, control the structure and transcriptional permissiveness of chromatin. The crosstalk between DNA methylation and histone modification is a basis for regulation of the functional genome. If these mechanisms run rogue, as in malignant cells, they may force cells into fixed de-differentiated states. The initial epigenetic errors may arise through alterations of mechanisms triggered by external impact, such as chemical agents, inflammation, or pathogens such as viruses, as we and others have previously reported $(27,31,32)$. It is thus of great importance to understand which external factors may manipulate the epigenome in such a way that the target cells respond abnormally to their environment or become reprogrammed. In addition, the original notion that DNA methylation is a guardian against invading foreign nucleic acids provides a logical explanation to a viral mechanism keeping newly replicated virus DNA methylationfree by preventing DNMTs from functioning in the nucleus.

In agreement with the idea that DNA methylation might prevent viral replication and/or transcription, the inhibition of methylation by $5 A Z A$ is expected to influence active viral infection. Indeed, the number of HCMV-positive cells was increased following $5 A Z A$ treatment in both D324 cells and HUVECs, suggesting the benefits of a hypomethylated milieu for viral production. This may have important implications for the treatment of $\mathrm{MB}$ with epigenetic drugs, since an increased number of HCMV-IE- and HCMV-gB-positive cells could contribute to the oncomodulatory effects of HCMV infection in MB. HCMV-IE proteins are viral regulatory proteins and transcription factors that act as oncomodulatory proteins through different mechanisms such as causing instability in chromosomes 1q42 and 1q21 $(33,34)$, interfering with p53, controlling p21 degradation and phosphorylated retinoblastoma $(\mathrm{pRb})$ proteins. These oncomodulatory activities result in uncontrolled cellular proliferation and transition to the $S$ phase of the cell cycle $(35,36)$. A still unanswered question is whether $5 A Z A$ treatment alters the host methylome and thereby its gene regulation. Although host cell replication is attenuated by HCMV infection and passive demethylation of the host genome cannot take place, as we demonstrated for non-tumor cell types infected with HCMV (27), it is still possible that $5 A Z A$ can induce active demethylation through the induction of Tet enzymes, and could therefore cause changes to the methylome of the host cells. This issue will be further investigated.

Inflammation is one of the recently established hallmarks of cancer, and in theory the relocation of DNMT-1 into the cytoplasm of HCMV-infected endothelial cells could contribute to increased induction of inflammatory factors important for vascularization and angiogenesis, such as VEGF, FGF, IL-8 and IL-6. Inflammation is in fact one of the key factors in the progression of $\mathrm{MB}$, and anti-inflammatory drugs including the COX2 inhibitor celecoxib has been suggested to be used in these patients (37). Importantly, HCMV infection of the cells in vitro leads to increased induction of $\mathrm{COX} 2$, and COX2 inhibitors reduce viral replication (38). Furthermore, we previously reported substantial reduction in tumor growth by the antiviral drug Valcyte ${ }^{\circledR}$ and by celecoxib, both in vitro and in vivo (19).

In conclusion, DNMT-1 localized to the cytoplasm in HCMV-infected MB and endothelial cells expressing HCMV late genes. Increased viral replication in 5AZA-treated infected cells suggests that HCMV replication benefits from a lack of DNA methylation activity in host cells. The concept of epigenetic therapy is currently under consideration for MB (39), and since our findings raise the possibility that epigenetic modulation can directly impact the level of viral replication, this should be considered in the design of epigenetic MB therapies.

\section{Acknowledgements}

The authors would like to acknowledge the Swedish Cancer Foundation, the Swedish Children Cancer Foundation, the Swedish Society for Medical Research (SLS), Goljes Memory Foundation, Magnus Bergvalls Foundation, Swedish Society for Medical Research (SSMF), the Karolinska Institutet Foundations and Tore Nilsson's Foundation.

\section{Competing interests}

The authors declare that they have no competing interests.

\section{References}

1. Mulhern RK, Merchant TE, Gajjar A, Reddick WE and Kun LE: Late neurocognitive sequelae in survivors of brain tumours in childhood. Lancet Oncol 5: 399-408, 2004.

2. Rood BR, Macdonald TJ and Packer RJ: Current treatment of medulloblastoma: Recent advances and future challenges. Semin Oncol 31: 666-675, 2004.

3. American Society of Clinical Oncology (ASCO): Medulloblastoma - Childhood: Statistics. https://www.cancer.net/ cancer-types/medulloblastoma-childhood/statistics. Accessed Aug, 2016.

4. Oeffinger $\mathrm{KC}$ and Hudson MM: Long-term complications following childhood and adolescent cancer: Foundations for providing risk-based health care for survivors. CA Cancer J Clin 54: 208-236, 2004.

5. de Bont JM, Packer RJ, Michiels EM, den Boer ML and Pieters R: Biological background of pediatric medulloblastoma and ependymoma: A review from a translational research perspective. Neuro-oncol 10: 1040-1060, 2008.

6. Thompson MC, Fuller C, Hogg TL, Dalton J, Finkelstein D, Lau CC, Chintagumpala M, Adesina A, Ashley DM, Kellie SJ, et al: Genomics identifies medulloblastoma subgroups that are enriched for specific genetic alterations. J Clin Oncol 24: 1924-1931, 2006.

7. Hartmann W, Koch A, Brune H, Waha A, Schüller U, Dani I, Denkhaus D, Langmann W, Bode U, Wiestler OD, et al: Insulin-like growth factor II is involved in the proliferation control of medulloblastoma and its cerebellar precursor cells. Am J Pathol 166: 1153-1162, 2005.

8. Remke M, Hielscher T, Korshunov A, Northcott PA, Bender S, Kool M, Westermann F, Benner A, Cin H, Ryzhova M, et al: FSTL5 is a marker of poor prognosis in non-WNT/non-SHH medulloblastoma. J Clin Oncol 29: 3852-3861, 2011.

9. Kawauchi D, Robinson G, Uziel T, Gibson P, Rehg J, Gao C, Finkelstein D, Qu C, Pounds S, Ellison DW, et al: A mouse model of the most aggressive subgroup of human medulloblastoma. Cancer Cell 21: 168-180, 2012.

10. Northcott PA, Lee C, Zichner T, Stütz AM, Erkek S, Kawauchi D, Shih DJ, Hovestadt V, Zapatka M, Sturm D, et al: Enhancer hijacking activates GFI1 family oncogenes in medulloblastoma. Nature 511: 428-434, 2014. 
11. Robinson G, Parker M, Kranenburg TA, Lu C, Chen X, Ding L, Phoenix TN, Hedlund E, Wei L, Zhu X, et al: Novel mutations target distinct subgroups of medulloblastoma. Nature 488: 43-48, 2012.

12. Hovestadt V, Jones DT, Picelli S, Wang W, Kool M, Northcott PA, Sultan M, Stachurski K, Ryzhova M, Warnatz HJ, et al: Decoding the regulatory landscape of medulloblastoma using DNA methylation sequencing. Nature 510: 537-541, 2014.

13. Lin CY, Erkek S, Tong Y, Yin L, Federation AJ, Zapatka M, Haldipur P, Kawauchi D, Risch T, Warnatz HJ, et al: Active medulloblastoma enhancers reveal subgroup-specific cellular origins. Nature 530: 57-62, 2016.

14. Watanabe $\mathrm{Y}$ and Maekawa M: Methylation of DNA in cancer. Adv Clin Chem 52: 145-167, 2010.

15. Feinberg AP, Koldobskiy MA and Göndör A: Epigenetic modulators, modifiers and mediators in cancer aetiology and progression. Nat Rev Genet 17: 284-299, 2016.

16. Lister R, Pelizzola M, Dowen RH, Hawkins RD, Hon G, Tonti-Filippini J, Nery JR, Lee L, Ye Z, Ngo QM, et al: Human DNA methylomes at base resolution show widespread epigenomic differences. Nature 462: 315-322, 2009.

17. Ziller MJ, Gu H, Müller F, Donaghey J, Tsai LT, Kohlbacher O, De Jager PL, Rosen ED, Bennett DA, Bernstein BE, et al: Charting a dynamic DNA methylation landscape of the human genome. Nature 500: 477-481, 2013

18. Rondelet G and Wouters J: Human DNA (cytosine-5)-methyltransferases: A functional and structural perspective for epigenetic cancer therapy. Biochimie 139: 137-147, 2017.

19. Baryawno N, Rahbar A, Wolmer-Solberg N, Taher C, Odeberg J, Darabi A, Khan Z, Sveinbjörnsson B, FuskevÅg OM, Segerström L, et al: Detection of human cytomegalovirus in medulloblastomas reveals a potential therapeutic target. J Clin Invest 121: 4043-4055, 2011.

20. Rahbar A, Orrego A, Peredo I, Dzabic M, Wolmer-Solberg N, Strååt K, Stragliotto G and Söderberg-Nauclér C: Human cytomegalovirus infection levels in glioblastoma multiforme are of prognostic value for survival. J Clin Virol 57: 36-42, 2013.

21. Wolmer-Solberg N, Baryawno N, Rahbar A, Fuchs D, Odeberg J, Taher C, Wilhelmi V, Milosevic J, Mohammad AA, Martinsson T, et al: Frequent detection of human cytomegalovirus in neuroblastoma: A novel therapeutic target? Int J Cancer 133: 2351-2361, 2013.

22. Bartek J Jr, Fornara O, Merchut-Maya JM, Maya-Mendoza A, Rahbar A, Stragliotto G, Broholm H, Svensson M, Sehested A, Söderberg Naucler C, et al: Replication stress, DNA damage signalling, and cytomegalovirus infection in human medulloblastomas. Mol Oncol 11: 945-964, 2017.

23. Taylor-Wiedeman J, Sissons JG, Borysiewicz LK and Sinclair JH: Monocytes are a major site of persistence of human cytomegalovirus in peripheral blood mononuclear cells. J Gen Virol 72 2059-2064, 1991.

24. Emery VC: Investigation of CMV disease in immunocompromised patients. J Clin Pathol 54: 84-88, 2001.
25. Gaytant MA, Steegers EA, Semmekrot BA, Merkus HM and Galama JM: Congenital cytomegalovirus infection: Review of the epidemiology and outcome. Obstet Gynecol Surv 57: 245-256, 2002.

26. Liu XF, Wang X, Yan S, Zhang Z, Abecassis M and Hummel M: Epigenetic control of cytomegalovirus latency and reactivation. Viruses 5: 1325-1345, 2013.

27. Esteki-Zadeh A, Karimi M, Strååt K, Ammerpohl O, Zeitelhofer M, Jagodic M, Mehrab-Mohseni M, Sjöholm L, Rahbar A, Söderberg-Nauclér C, et al: Human cytomegalovirus infection is sensitive to the host cell DNA methylation state and alters global DNA methylation capacity. Epigenetics 7: 585-593, 2012.

28. Estécio MR and Issa JP: Dissecting DNA hypermethylation in cancer. FEBS Lett 585: 2078-2086, 2011.

29. Kanherkar RR, Bhatia-Dey N and Csoka AB: Epigenetics across the human lifespan. Front Cell Dev Biol 2: 49, 2014.

30. Lindsey JC, Lusher ME, Anderton JA, Bailey S, Gilbertson RJ, Pearson AD, Ellison DW and Clifford SC: Identification of tumour-specific epigenetic events in medulloblastoma development by hypermethylation profiling. Carcinogenesis 25 : 661-668, 2004

31. Bayarsaihan D: Epigenetic mechanisms in inflammation. J Dent Res 90: 9-17, 2011

32. Gómez-Díaz E, Jordà M, Peinado MA and Rivero A: Epigenetics of host-pathogen interactions: The road ahead and the road behind. PLoS Pathog 8: e1003007, 2012.

33. Cinatl J Jr, Vogel JU, Kotchetkov R and Wilhelm Doerr H: Oncomodulatory signals by regulatory proteins encoded by human cytomegalovirus: A novel role for viral infection in tumor progression. FEMS Microbiol Rev 28: 59-77, 2004.

34. Fortunato EA, Dell'Aquila ML and Spector DH: Specific chromosome 1 breaks induced by human cytomegalovirus. Proc Natl Acad Sci USA 97: 853-858, 2000.

35. Prichard MN, Sztul E, Daily SL, Perry AL, Frederick SL, Gill RB, Hartline CB, Streblow DN, Varnum SM, Smith RD, et al: Human cytomegalovirus UL97 kinase activity is required for the hyperphosphorylation of retinoblastoma protein and inhibits the formation of nuclear aggresomes. J Virol 82: 5054-5067, 2008.

36. Herbein $G$ and Kumar A: The oncogenic potential of human cytomegalovirus and breast cancer. Front Oncol 4: 230, 2014

37. Baryawno N,Sveinbjörnsson B, Eksborg S, Orrego A, SegerströmL, Oqvist CO, Holm S, Gustavsson B, Kågedal B, Kogner P and Johnsen JI: Tumor-growth-promoting cyclooxygenase-2 prostaglandin E2 pathway provides medulloblastoma therapeutic targets. Neuro Oncol 10: 661-674, 2008.

38. Zhu H, Cong JP, Yu D, Bresnahan WA and Shenk TE: Inhibition of cyclooxygenase 2 blocks human cytomegalovirus replication. Proc Natl Acad Sci USA 99: 3932-3937, 2002.

39. MacDonald TJ, Aguilera D and Castellino RC: The rationale for targeted therapies in medulloblastoma. Neuro-oncol 16: 9-20, 2014. 